\title{
Configurações
}

Revista Ciências Sociais

\section{A promoção centrífuga do ensino da sociologia}

The centrifugal promotion of the teaching of sociology

La promotion centrifuge de l'enseignement de la sociologie

\section{ANTÓNIO PEDRO DORES}

\section{(2) OpenEdition}

\section{Journals}

Edição electrónica

URL: https://journals.openedition.org/configuracoes/14659

DOI: 10.4000/configuracoes.14659

ISSN: 2182-7419

\section{Editora}

Centro de Investigação em Ciências Sociais

Edição impressa

Paginação: 159-174

ISSN: 1646-5075

\section{Refêrencia eletrónica}

ANTÓNIO PEDRO DORES, «A promoção centrífuga do ensino da sociologia», Configurações [Online], 28 | 2021, posto online no dia 28 dezembro 2021, consultado o 30 dezembro 2021. URL: http:// journals.openedition.org/configuracoes/14659; DOI: https://doi.org/10.4000/configuracoes.14659 
DORES, António Pedro - A promoção centrífuga do ensino da sociologia. Configurações [em linha]. 28 (2021) p. 159-174.

\title{
A promoção centrífuga do ensino da sociologia
}

\author{
ANTÓNIO PEDRO DORES*
}

Instituto Superior de Ciências do Trabalho e da Empresa - Instituto Universitário de Lisboa

\begin{abstract}
Resumo
A ciência prestigiou-se pela sua capacidade de antecipar o futuro, prevendo-o e construindo-o. As ciências sociais têm nas transformações em curso uma oportunidade para continuarem o caminho entre a filosofia social e a ciência, libertando-se da conjuntura histórica que as pararam algures entre as humanidades e a ciência. O sucesso de um tal empreendimento seria útil para o aumento do prestígio da ciência, para a educação das novas gerações e para a adaptabilidade da humanidade à nova era geológica que se anuncia. A educação em sociologia pode ter um papel nesse processo.
\end{abstract}

Palavras-chave: ciência, transformação, profissão, humanização, Império.

\section{Abstract \\ The centrifugal promotion of the teaching of sociology}

Science is renowned for its ability to anticipate the future, foreseeing and building it. The social sciences have an opportunity, among the ongoing transformations, to resume the path between social philosophy and science, freeing itself from the historical conjuncture that froze them somewhere between humanities and science. The success of such an undertaking would be useful for increasing the prestige of science, for the education of new generations, and for the adaptation of humanity to the upcoming new geological era. Education in sociology may have a role to play in this process.

Keywords: science, transformation, profession, humanisation, Empire.

\section{Resumé}

La promotion centrifuge de l'enseignement de la sociologie

La science est réputée pour sa capacité à anticiper, prévoir et construire le futur. Les sciences sociales ont une opportunité. dans les transformations en cours. de poursuivre *E-mail: antonio.dores@iscte.pt | ORCID ID: http://orcid.org/0000-0002-5482-6196 
leur chemin entre la philosophie sociale et la science, en se libérant de la conjoncture historique qui les a arrêtées quelque part entre les sciences humaines et la science. Le succès d'une telle entreprise serait utile pour accroître le prestige de la science, pour l'éducation des nouvelles générations et pour l'adaptabilité de l'humanité à la nouvelle ère géologique qui s'annonce. L'éducation en sociologie peut avoir un rôle dans ce processus.

Mots-clés: science, transformation, profession, humanisation, Empire.

\section{Introdução}

A crise financeira de 2008 fez recordar a de 1929. Fez recordar o New Deal, a política norte-americana que projetou os EUA para fora da Grande Recessão e que esteve na base da construção da superpotência que emergiu como centro do império em que a Europa ocidental se incluiu, depois da destruição radical da Europa na segunda Guerra Mundial.

Polanyi (1980) chamou grande transformação ao estudo de referência que fez dessa época e que inspira sociólogos, economistas e políticos. Essa transformação promoveu engenheiros e professores a papéis estratégicos de reconstrução das sociedades transformadas em capitalismo avançado (Bell, 1973). Nos anos 1980, estas profissões perderam o protagonismo para os economistas e os advogados (Reich, 1991), os analistas simbólicos percursores dos codificadores digitais (Pistor, 2019). Os professores de sociologia foram promovidos na primeira fase histórica da grande transformação (Coser, 1956, p. 18-29). Em Portugal, com o atraso de três décadas causado pelo reacionarismo do Estado Novo, a profissionalização dos sociólogos também aconteceu (Machado, 1996, p. 49 e 59). Com o sucesso e expansão do neoliberalismo, promotor da ideia there is no such thing as society, Sra. Thatcher dixit, o prestígio da profissão passou a ser politicamente atacado a partir dos anos 1980, enquanto as ofertas educativas e as oportunidades de investigação social aumentavam em Portugal (Machado, 1996). Os minuciosos e burocráticos controlos financeiros e avaliativos do trabalho, incluindo do trabalho científico e educativo, evoluíram e acabaram em campos universitários e científicos digitais que se radicalizam, hoje, na banalização da teleformação.

\section{1. Ânimos divididos}

Entre os profissionais com formação em sociologia, há os que se apresentam orgulhosamente como sociólogos, beneficiando de uma dinâmica associativa singular (Costa, 2004, p. 47); outros têm pudor de o fazer (Costa, 2004, p. 52). Não se sentem autorizados para tal por um mero certificado escolar, que lhes parece insuficiente para o prestígio que reconhecem na profissão, e/ou optam 
por se associar a outras profissões que pensam serem mais pertinentes (ISCTEIUL, 2021, p. 21). Os dados mostram existir uma base objetiva para o prestígio do sociólogo professor universitário vigorar sobre e distante da maioria da profissão.

Misto de admiração, complexo de inferioridade e perplexidade perante os mercados de trabalho, à saída dos cursos de sociologia, os recém-graduados perguntam-se para que servem e o que são, exatamente, as competências adquiridas. As estatísticas referidas mostram que, passado um ano da conclusão da licenciatura, metade dos licenciados empregados trabalha "em área completamente diferente" e um terço faz aproximações inovadoras à profissão (ISCTEIUL, 2021, p. 21). Os professores também se perguntam e hesitam. Será que formam cientistas, animadores culturais, técnicos de integração social, pessoal para as $\mathrm{ONG}$, especialistas em tratamento de dados e estatísticas, cidadãos? A dúvida sobre se as ciências sociais e a sociologia são realmente ciências, e se ser sociólogo é mesmo uma profissão, acompanha e reforça a prática de os sociólogos se definirem como especialistas numa qualquer subdisciplina ou numa outra profissão. A representação da sociologia como um mundo exterior à prática profissional predominante dos sociólogos, estacionada entre as humanidades e a ciência (Darhendorf, 1958), apesar dos esforços em contrário, tem-se reproduzido (Machado, 1996, p. 61-62). Falta ao ensino da sociologia, em perda de estudantes, ânimo de convicção para o "empreendimento sociológico" (Quaresma, 2015) no mundo em mudança negativa (Casanova e Almeida, 2021, p. 29).

\section{A era do espírito punitivo}

A grande transformação do tempo de Polanyi não é repetível. Uma nova guerra mundial, como a que fez surgir os EUA como superpotência atómica, tornou-se inviável. Hoje, vários países são capazes de destruir várias vezes o planeta. Mas alguma forma de transformação está a ocorrer (Harari, 2018). Cabe aos sociólogos, e em especial aos professores de sociologia e às instituições em que trabalham, deixar de privilegiar a teoria da mudança social por impacto exterior singelo, como o tecnológico, e valorizar as dinâmicas sociais (Burawoy, 2004). As mudanças impostas por via digital são tão reais como as impostas pelo novo Z eitgeist político que se vem incorporando nas pessoas através das redes sociais, incomodadas com a sociedade da vigilância (Lyon, 2001; Staples, 1997).

As teorias sociais sabem que não basta considerar os efeitos de estrutura, de cima para baixo. Há também os efeitos da ação humana, de baixo para cima, no meio ambiente e nas instituições. As consciências (Damásio, 2020) e os micropoderes (Foucault, 1999) em rede (Castells, 2004) podem ser estimulados para produzir predominância de estados de espírito punitivos (Dores, 
2010). A transformação atualmente em curso pode ser descrita como uma radicalização do uso do espírito punitivo, alimentado primeiro nos casos de polícia (Wacquant, 2000) e, depois de 2008, trazido ao protagonismo político. Caberá às ciências sociais compreender e ajudar a fabricação de estados de espírito empáticos e solidários, em vez de assistir aos acontecimentos?

Desde os anos 1970, o proibicionismo (Woodiwiss, 1988) e as políticas de fins que justificam os meios (Perkins, 2004; Woodiwiss, 2005) prepararam o terreno para a banalização da guerra. Após a declaração dos Açores em 2003, assistiu-se à violação intencional do direito internacional e dos direitos humanos, como nos casos de Manning, Assange e Snowden, do destrato de prisioneiros de guerra, de imigrantes e refugiados, de Guantanamo, de Abu Grahib, das prisões secretas da CIA, dos maus tratos praticados nas fronteiras da UE contra os refugiados sírios em 2015, do trato com a Turquia para os conter, alargando uma política mediterrânica anterior. Os fins não são erradicar a pobreza ou a fome ou a guerra, apesar das intenções proclamadas pela ONU. Os fins são outros e inconfessáveis (Varoufakis, 2017).

Com a pandemia, as críticas ao funcionamento da comunicação social rivalizam com as críticas às práticas das redes sociais que com ela concorrem. Observa-se uma segmentação instigada do público em grupos de amizade e maldizer, em torno de antagonismos maniqueístas de vária índole. A dramatização que chama a atenção e usa as tecnologias de publicidade entretanto incorporadas na vida política e mediática, torna difícil organizar prioridades adequadas a exercícios de racionalidade. Perante a radicalização do maniqueísmo mediático, militar, político, ideológico, emocional, que alimenta as rodas do poder, caberá às ciências sociais não perder de vista os valores humanistas, como a sobrevivência da espécie e das crianças? Se a resposta for afirmativa, há que estudar os cuidados indispensáveis para que o futuro da humanidade se transforme em esperança, em vez do beco sem saída que parece ser atualmente.

Os telejornais anunciaram que as escolas fechadas por força da pandemia mantêm as cantinas abertas para dar de comer a muitas crianças cuja única refeição é fornecida pela escola. Num estado em que as crianças constituem uma parte de leão dos pobres, o espírito assistencialista que domina a sociedade do estado social (Dores, 2020) suscitou uma ideia ao ministro da educação: apresentou-se aos jornalistas para dizer, orgulhosamente, que, mesmo fechadas, as escolas continuam a cumprir papéis sociais, como o de restauração para os pobres.

Este episódio não mereceu referências. Há um consenso sobre a inevitabilidade de as sociedades modernas do século XXI serem impotentes contra a fome, a pobreza e a reprodução precoce das desigualdades de oportunidades incorporadas nas crianças. O aumento continuado de rendimentos de alguns dos muito ricos, contrasta com o aumento das desigualdades (Casanova e Almeida, 2021). Vive-se uma continuidade, radicalizada, do que se tem 
praticado nas últimas décadas. Ao mesmo tempo, por razões ecológicas, financeiras, sanitárias e geopolíticas, é evidente a necessidade e inevitabilidade de transformações. Elas ocorrerão conduzidas pela razão, caso haja competência preditiva adequada à ocasião, ou não.

A sociologia centrípeta, a que hoje se pratica, sem perder o foco nos estudos do poder, poderia transformar-se em sociologia centrífuga: sociologia aberta ao estudo dos cuidados prestados às pessoas, em especial às crianças, e ao modo como tais cuidados condicionam a produção incorporada de identidades pessoais e sociais discriminatórias, elitistas e dissimuladas, bem evidentes na pobreza envergonhada que se expande com a pandemia, como uma pandemia. Uma sociologia aberta às práticas terapêuticas e de prevenção de consequências das catástrofes, sejam elas naturais ou produzidas e reproduzidas pela ação humana. Há muita necessidade disso, agora e no futuro. Há muito a fazer para que a sociologia se disponha a colaborar nesse tipo de tarefas.

\section{Sociologia, o poder e as profissões que inspira}

No Congresso Português de Sociologia de 2021, na semiplenária sobre o ensino da sociologia, Luís Baptista chamou a atenção para a redução da influência da sociologia. Informou que deixaram de existir telefonemas, em tempos frequentes na Associação Portuguesa de Sociologia, a pedir a indicação de colegas para colaborarem em diagnósticos sociais. Nas livrarias, notou, as secções de sociologia viram-se reduzidas e afastaram-se das prateleiras da ciência. Os cursos universitários especializados atraem mais estudantes do que os cursos de sociologia. As novas práticas de acesso à informação dificultam a disponibilidade das pessoas para a reflexão demorada e amadurecida. Paulatinamente, seja por via da disponibilidade imediata de informação na Internet, seja pelo apelo hipnotizante dos ecrãs e das imagens que distorcem os textos, seja pela criação virtual e comercial de grupos de consensos autossatisfatórios nas redes sociais, seja por efeito do ensino de massas que educa os jovens a autodesresponsabilizarem-se pelo respetivo desempenho, uma profecia panótica auto-realiza-se como um pesadelo para os que continuam a avisar contra os riscos da decadência da democracia (D. F. do Amaral, 2003).

Depois de um período de forte crescimento da influência universitária e pública da sociologia em Portugal, a partir dos mínimos impostos pelo regime do Estado Novo até à construção de uma das maiores associações nacionais de sociologia do mundo (Machado, 1996, p. 58), há sinais de perda de influência, em linha com a experiência anterior dos principais campos sociológicos internacionais. A apropriação pública dos saberes profissionais dos sociólogos, como o inquérito e a análise de dados, mas também das nossas teorias ("É o sistema!", tornou-se uma frase banal para o vulgo se referir às estruturas sociais, conspirativas e inacessíveis), faz com que os discursos sociológicos surjam à 
mente do público como banalidades, como ideias já inscritas na linguagem. O desinteresse pela sociologia decorre do seu profundo sucesso. É recomendado que a sociologia (centrípeta) se afaste desse sucesso (transformando-se em sociologia centrífuga) para poder vingar.

A humildade da disposição de acompanhar e utilizar as análises sociais dos mestres transformou-se em elitismo profissional competitivo, assediado pelas políticas internacionais de investigação académica e pelas dinâmicas depressivas dos mercados de trabalho. A vontade de aprender para melhor intervir antes e depois da revolução, que inaugurou o crescimento da sociologia em Portugal, tornou-se num negócio de prestação de serviços produtores de empregabilidades culpabilizantes dos profissionais. Muitos impreparados para usar os instrumentos abstratos ensinados nos cursos e sem apoios interpares que as profissões mais antigas desenvolveram no seio das próprias empresas em que trabalham.

Ao adotarem estratégias de financiamento e avaliação de standard, divididas pela competição global cujos lugares de topo estão reservados à língua inglesa, as universidades adotaram uma postura defensiva, reforçando o complexo de inferioridade próprio das ciências sociais. A (des)valorização da língua portuguesa no quadro da ciência é disso um exemplo. Não há internacionalização do campo científico estruturado de forma competitiva sem a renúncia à promoção intelectual, cognitiva e política das línguas secundárias e locais, sem a valorização de quem tenha competências privilegiadas nas línguas e culturas anglo-saxónicas imperialistas, sequelas do esgotado império português.

Poderá a promoção estruturada do conformismo e da resignação, a que as circunstâncias parecem obrigar a sociologia e o português nas universidades, ser descontinuada e combatida? A sociologia poderá tornar-se um foco de afirmação do espírito científico que a política contra a pandemia revelou ser central para os destinos do planeta. Para isso, há que trocar a postura promocional do prestígio adquirido pelo estado social que profissionalizou as ciências sociais (Coser, 1956, p. 27). Isso teve por resultado estacionar as ciências sociais entre as humanidades e as ciências, ocupando-se da apologia do seu empregador, o estado social (Dores, 2020). A sociologia, os sociólogos e as suas instituições, podem decidir retomar o caminho já percorrido entre a filosofia social e as ciências, aproximando-se, em vez de se incompatibilizarem, com as ciências naturais.

Contra a hiperespecialização imposta pelas políticas tecnocientíficas internacionais dominadas pelo utilitarismo, que resulta em sociologia estanque às outras disciplinas das ciências sociais e a outros saberes, como o direito, a história, a ecologia, em contracorrente podem os sociólogos encetar um trajeto de modernização da inspiração clássica (Comte, Marx, Parsons) de promoção da orgulhosa irreverência científica na procura da verdade, sem compromissos nem com as fake news nem com a propaganda belicista, escamoteadoras 
das práticas antissociais das elites, aos níveis ecológico, financeiro, sanitário, moral.

\section{Avaliar o caminho percorrido}

O facto de sabermos hoje quão erradas e contraditórias foram algumas das formulações destes autores clássicos e dos seus seguidores é apenas mais um argumento a favor de que nos atrevamos a ser contraditórios e a arriscar errar, esperando que controvérsias possam distinguir as inovações pertinentes do modo eventualmente desajeitado e incompleto como são apresentadas. Para podermos seguir as pisadas dos nossos autores de referência, de forma mais profícua, havemos de aprender a organizar condições institucionais de produção de ciência tão aberta, fraternal, colaborativa, efetiva e livre quanto possível.

A fragilidade política da sociologia em Portugal pode ser evidenciada pelo facto de as disciplinas de ensino da sociologia, nos cursos não superiores, serem lecionadas prioritariamente por licenciados em outras disciplinas das ciências sociais, ou pelo facto de não haver uma ordem dos sociólogos. Como explicou Max Weber aos seus alunos e admiradores, à saída da primeira Grande Guerra, o espírito científico está vocacionado para competências distintas do espírito político (Weber, 2012b, 2012a). A classe dos sociólogos não se quis comprometer explicitamente com a tendência geral de profissionalização (Freire, 2003), embora também não tenha rompido com o espírito corporativo e hierárquico. A Associação Portuguesa de Sociologia, associação científica e profissional, jamais representou os profissionais não docentes nos seus órgãos sociais com a paridade que as declarações públicas poderiam levar a querer dever ser o caso.

Para reforçar o desempenho político da sociologia e dos sociólogos, há que evitar as cedências à autossatisfação acrítica das práticas profissionais e do ensino. Dito de outro modo, há que abrir espaço para a produção ideológica no seio das ciências sociais, que não esteja condicionada à polarização gerada pela Guerra Fria e que continua a distanciar as sociologias ensinadas em diferentes escolas, as teorias críticas das teorias realistas, as teorias sociológicas das teorias sociais, etc. Sem deixar de dar atenção às questões de poder, há que não ficar refém delas. Há que compreender como os cuidados produzem identidades sociais que incorporam disposições manipuladas e irredutíveis às práticas de poder. $\mathrm{Na}$ verdade, a maior parte da vida em sociedade é para prestar cuidados - cada vez mais mercantilizados, é certo - uns aos outros. Uma tal abertura poderá criar novos espaços de liberdade e circulação de práticas, ideias e ideais dentro da sociologia, como resposta aos anseios identitários que hoje se canalizam para fora da nossa disciplina.

A ciência hiperdisciplinada para fins utilitários nunca funcionou plenamente (Schofield, 2018). Mas funciona o suficiente para impedir a liberdade de circulação, condicionada pelos moralismos identitários inerentes à polarização 
ideológica e estratégica belicista, que continua apesar do fim da Guerra Fria. Continua-se a obrigar os estudantes a escolher a respetiva orientação ideológica antes de conhecerem os argumentos científicos avançados pelas diferentes escolas de ciências sociais. Enquanto isso, ambas as ideologias e estratégias polarizadas e dominantes nas ciências sociais partilham entre si a mesma base cartesiana de apologia da supremacia humana, na verdade, patriarcal e colonial imperialista, contra a natureza e contra a parte da humanidade desumanizada sob a forma de recursos humanos. A centralidade das lutas pelo poder no mundo académico a isso obriga. Conformando as identidades pessoais e profissionais dos sociólogos como se referiu acima.

Dividir para reinar é uma estratégia básica de subordinação, cujos resultados práticos são evidentes na dispersão das ciências sociais entre si e dentro de si, acossados pelas políticas de financiamento e de avaliação. A rutura com tais ideologias está em curso (Clark e Szerszynski, 2020; Damásio, 1994, por exemplo) e mostra como a ideologia e a ciência podem e devem dialogar fora dos constrangimentos belicistas da circulação da informação que dominam as ambições imperiais e se estruturam globalmente de um modo que paralisa a capacidade da humanidade para reagir aos prognósticos científicos, sejam eles sobre o aquecimento global, sobre a sucessão de crises económicas, sobre como resolver os problemas da dívida ou da miséria, ou sobre como enfrentar pandemias.

O poder da ciência e as liberdades universitárias estão a ser usados, embora não estejam a ser institucionalmente apoiadas para combater as ideologias dos financiadores e avaliadores que exploram a ciência, como o fazem com tudo o que podem (Pistor, 2019). A distância entre os académicos e os profissionais, entre os teóricos e os práticos, entre as disciplinas e o trabalho dos licenciados, cavada também por estatutos sociais e ocupacionais diferenciados em termos de preocupações e obrigações para com a ciência e as liberdades, pode ser atacada de forma voluntária, consciente. As instituições, por seu lado, têm conseguido impor aos académicos restrições profissionais das respetivas liberdades, através da precarização do trabalho, no sentido inverso das conquistas que os nossos antepassados impuseram, por exemplo, em contratos académicos de tenure.

A sociologia ensina a ter cuidado com a antropologização das classificações: os profissionais e as instituições não são homogéneos. Ao invés, são conflituais. São essas as brechas por onde as iniciativas de base, as iniciativas voluntaristas, de resistência, sabotagem, mas também - é essa a ambição que aqui se suscita - construtivas, esperançosas, animadas, ambiciosas, eventualmente clandestinas, podem romper com as divisões hiperdisciplinares, redutoras das ideologias e da moral aos cânones promovidos a favor das elites.

Os académicos, as instituições, os profissionais, as ciências sociais e as ciências conhecem, no seu seio, tendências conformistas, atualmente dominantes, e 
tendências centrífugas, ambiciosas, alegres, comunicativas, entusiasmadas. O contínuo agravar e multiplicar das tensões de sucessivas e cumulativas crises, os desentendimentos entre as finalidades institucionalmente declaradas, como as dos objetivos do milénio da $\mathrm{ONU}$, e as realidades observáveis, os resultados da ação humana, estão a aumentar o espaço, dentro da mente das pessoas e dentro das práticas instituídas, para se fazer de modo diferente. Isso pode ser antecipado voluntaristicamente, com a vantagem de permitir algum controlo sobre o que se vier a passar, ou pode ser espoletado pelas circunstâncias desastrosas que acontecem cada vez com mais regularidade em diferentes partes do mundo.

\section{Limites da profissionalização}

A experiência mostra como, nas últimas décadas, a integração de profissionais com intensas formações científicas tem sido feita em detrimento da ciência relativamente ao profissionalismo (O N Neil, 2016; Supiot, 2015). O facto de a Associação dos Sociólogos se organizar ao inverso desta tendência pode significar uma oportunidade para desenvolver a ciência, o espírito científico, caso as instituições de sociologia e de outras ciências sociais não se resignem à situação e entendam o significado político de retomar o trajeto abandonado de se transformarem em ciências, como as ciências naturais.

Observa-se uma crescente desvinculação entre as pessoas que aprendemos a ser e os indivíduos que nos forçamos a ser para integrar as sociedades a que desejamos pertencer. Além dos problemas de saúde mental inerentes a uma tal situação, a sensação de desorientação leva também a um acolhimento de disposições violentas, irracionais, que anteriormente não se expressavam politicamente. A ciência, e bem, é chamada a ajudar a orientar políticas desorientadas pela pandemia e pela continuação de uma crise financeira que se tem vindo a esconder. A ciência que apareceu em público, mal, deixou capturar-se pelo profissionalismo, pela propaganda, pelo ilusionismo político, pela resignação, conduzida pela ideia de voltar ao normal, como se as pessoas, a história, as sociedades fossem algo diferente do devir. Como se toda a humanidade estivesse prostrada a fazer de cadáver numa maca de hospital, em confinamento, à espera que a pandemia passe, que o vírus desapareça.

A característica das instituições que as faz organizar campanhas de humanização para poderem subsistir, por se reconhecerem desumanas, revela-se estruturalmente (no sentido de Parsons) nos padrões de valor cartesianos. Faz parte desses valores a supremacia da res cogitans face à res extensa, da humanidade em relação à natureza, da civilização em relação às culturas, do cérebro relativamente aos corpos (Fragoso, 2021), dos vencedores face aos perdedores, dos trabalhadores intelectuais face aos trabalhadores manuais, dos patrões face aos trabalhadores. Na linguagem das ciências sociais, as desigualdades não 
param de crescer. Resultam de padrões usados, como os recursos humanos, para excluir a maior parte da humanidade, incluindo os profissionais, do papel de acumuladores reservado às elites (Dores, 2014). Cada pessoa, ao tornar-se profissional, de modo voluntário, frequentemente consciente do sacrifício que o trabalho representa e impotente para o evitar, oferece às elites o individuo que formou em si, registado formalmente em currículos vitae, nomeadamente através da escolarização e da formação científica. Fá-lo como forma de integração social e de superiorização em relação aos excluídos, marginalizados, estigmatizados.

\section{Como e o que fazer? Por uma sociologia centrífuga}

Comte entusiasmou-se com uma filosofia positiva, a que deu também o nome de sociologia, ciência integrativa da mais alta complexidade. Engels chamou socialismo científico aos materialismos histórico e dialético de Marx, para enobrecer o seu entusiasmo proletário. Durkheim usou a sua cátedra de educação para ensinar o sentido sociológico da solidariedade. Parsons fundou o profissionalismo sociológico no diálogo entre a teoria de sistemas, capaz de dar conta das estruturas sociais, e a teoria da ação, orientadora das finalidades do controlo social que ocupam os sociólogos.

$\mathrm{Na}$ prática da formação dos profissionais de sociologia, o que vingou foram as teorias de médio alcance, como Merton (1948) previra. O estrutural-funcionalismo normalizou-se como subconsciência dos sociólogos (Mouzelis, 1995, p. 7). No campo da economia, a rainha das ciências sociais, os avanços científicos foram revertidos (Skidelsky, 2018) e as teorias desapareceram da vida da esmagadora maioria dos estudantes e dos profissionais da disciplina (J. F. do Amaral et al., 2008). É certo que os cursos de sociologia não foram tão longe, ao menos aparentemente, nesta tendência de sacrifício da reflexão ao profissionalismo. Há cadeiras de teorias sociológicas nas licenciaturas. Mas a liberdade de opção ideológica está condicionada à ideologia predominante em cada escola. O que significa discriminações contra ideologias ou meras intuições desajustadas à promoção do espírito dominante em cada lugar. As faculdades de sociologia legitimam assim a subordinação implícita dos profissionais às ideologias locais das entidades empregadoras, sob a forma de conformismo. Assim se ensinam às ciências centrípetas, utilitárias, tecnociências, hiperespecializadas, segregadoras, e desfavoráveis às ciências centrífugas. Estas procuram continuar a intenção clássica das ciências sociais de se autonomizarem perante a tradição, as políticas e os pensamentos dominantes. As ciências centrífugas optam por criar alternativas às perspetivas cartesianas de redução sistémica dos objetos de estudo, tendo presente que os todos são outra coisa diferente da mera justaposição das partes. 
A ciência centrífuga é praticada. Mas pouco pode fazer face à hiperespecialização competitiva promovida pelas políticas de profissionalização dos cientistas e pela tendência de conquista académica e profissional de espaços de liberdade cognitiva fechados em si próprios. A liberdade dentro de muros e acossada pela concorrência, que inibe a colaboração e a troca de ideias, é panótica. A libertação reclama a conjugação de quem faz ciência centrífuga apoiada por instituições capazes de ampliar os espaços de liberdade dialogante, cognitiva e racional.

As distrações ideológicas e disciplinares induzidas pelas políticas científicas podem ser denunciadas e reconhecidas. Os estudos sociológicos podem abrir-se às tecnociências, não só como observações, mas também como participações num projeto de denúncia e reconhecimento das limitações das políticas de ciência (Schofield, 2018) que também condicionam as ciências sociais. A sociologia deve ser competente para estudar a dependência da vida humana das próteses tecnológicas que infraestruturam as nossas experiências (Latour, 2007), incluindo do espírito de modernização que liga a ação humana e a ação maquinal (Latour, 1992) e legal (Pistor, 2019). Precisa de se abrir às ciências naturais, como as que lidam com a energia (Morris, 2013), com a complexidade (Prigogine, 1996), com a vida (Damásio, 2020), com a biologia de que partiram alguns dos mais importantes autores clássicos da sociologia, mas, entretanto, intencional e moralmente apartada do convívio dos sociólogos.

Cabe um papel especial à sociologia no estudo das sociedades, nomeadamente o estudo das práticas de fusão de práticas parcelares que geram fenómenos novos, emergentes, evolutivos, de reconfiguração da vida e do meio ambiente, que são notórios desde a presença de vida na Terra e, especialmente, na ação da humanidade no meio ambiente.

A associação não é uma característica própria da humanidade: a matéria, através da gravidade, da eletricidade, do magnetismo, da formação de átomos, usa a associação para animar a evolução do universo, como se fosse uma história. Isso não nega a existência de sociedades humanas. Apenas reclama articular o conhecimento sobre o que sejam as sociedades humanas em experiências cósmicas (Hawking, 1988), incluindo evitar assistir à transformação de um objetivo meritório, o de praticar métodos holistas, em propaganda (Christian, 2021).

Não há conhecimento sem alguma base de irracionalidade e voluntarismo à mistura. A irracionalidade, as emoções, são indissociáveis dos sentimentos próprios da experiência humana, incluindo a dos cientistas. As instituições que lidam com a ciência, os cientistas e os estudantes, em vez de estimularem as suas emoções em termos competitivos, deveriam, antes, estimular o reconhecimento das vantagens e dos inconvenientes de usar diferentes tipos de emoções associativas (repugnância ou empatia, discriminação ou solidariedade, alheamento ou compromisso) para enfrentar melhor os problemas atuais.

A ciência centrífuga é ideológica, mas não no sentido nacionalista, partidário ou imperialista herdado da Guerra Fria e continuado depois dela. 
A especialização profissional e disciplinar da ciência centrípeta terá vantagem em confrontar-se e testar-se cognitivamente com os saberes produzidos fora das conchas profissionais e disciplinares, incomunicantes de proteção das liberdades condicionadas e prescritas, de forma defensiva. O aquecimento global, a falência financeira, a desproteção da democracia, a transição energética, a sustentabilidade alimentar, a liberdade de expressão, os principais problemas sociais do momento são globais e não parecem estar ao alcance de regimes incapazes de erradicar a fome, a miséria, a guerra.

\section{Conclusão}

A discussão clássica sobre se a sociedade moderna resulta da luta de classes, da responsabilização individual, da intensificação da solidariedade urbana, dos trabalhos de construção dos selves, foi normalizada, na verdade, abolida pela ideia de haver uma oposição ontológica entre as instituições e as pessoas, as superestruturas e o quotidiano. Separaram-se os estudos macrossociológicos dos microssociológicos e dos intermédios, como os dos mercados, dos espaços públicos, das organizações, da vida familiar, etc.

A dispersão hiperdisciplinar politicamente instigada no quadro da profissionalização das ciências sociais, no quadro do sucesso do New Deal, do Welfare Stare, do Estado Social, e das tecnociências que os servem, apartou os praticantes de ciências sociais entre si, valorizando relativamente os professores e desvalorizando os profissionais. A crescente institucionalização das tarefas de cuidados, através da restauração, nas escolas, nos hospitais, no acolhimento de crianças, jovens, doentes mentais, idosos, pobres, estrangeiros, grupos estigmatizados, é apoiada pelas ciências sociais de modo ideologicamente separado das vidas económica, política e cultural tratadas em abstrato, geralmente reduzidas a estatísticas.

A reflexão sobre o lugar da sociologia no mundo e na escola tornou-se rara, como foi reconhecido no simpósio organizado por Pierre Guibentif (2018). O ensino da teoria sociológica, além de separado do das outras teorias sociais no processo de redução dos anos do curso, ficou reduzida a metade do tempo de contacto com os estudantes e separado em equipas de docentes especializadas em períodos ou temas incomunicantes entre si (Dores, 2019). Profissionalmente isolados, aos docentes resta optar por seguir algum mestre, cujo culto de personalidade possa ser praticamente obrigatório para os estudantes, como marca do curso ou da faculdade. As liberdades académicas perdem o contraditório e o debate (Llano, 2021).

Os estudantes estão tacitamente treinados para procurar a proteção dos professores mais poderosos para os seus percursos escolares competitivos, como os diretores de curso. As universidades, contra a legislação em vigor, mantêm os hábitos de concentração das tarefas 
de orientação em professores açambarcadores, o que resulta em concentração de poder, limitações e distorções dos debates académicos.

Os estudantes universitários são o resultado de um ensino básico e secundário massificados que substituiu a finalidade de competências cognitivas pela de competências utilitárias, a orientação da sabedoria pela da empregabilidade, a inovação pela performatividade, isto é, foi substituindo a formação das elites, no pós-guerra, pela preparação para aceitação dos papéis sociais disponíveis. Como se pode observar pelas atividades organizadas pelas associações de estudantes, as praxes deixaram de ser a expressão dos que se preparam para ser os donos disto tudo - os licenciados - para renascerem sob a forma de subordinação orgulhosa a humilhações (Ferreira, 2014).

A situação de transformação tecnológica superacelerada, dita digitalização, a impotência da maior superpotência militar nuclear, que privatiza a guerra e, por isso, não obtém retorno financeiro suficiente, a par das transformações financeiras indispensáveis perante a dívida impagável e a transição anunciada da sede imperial de Londres e Nova Iorque para Pequim, num ambiente de transição geológica para o Antropoceno, faz com que o quotidiano esteja a reduzir a margem de manobra profissional dos sociólogos, como a de muitos outros profissionais.

Isolados nos seus mundos particulares, previamente desenhados para suportarem uma divisão de trabalho individualista, os sociólogos, professores, estudantes e profissionais podem decidir romper com a individualização das pessoas e de si próprios. Podem recriar com independência a sua arte com vista a prosseguir os desígnios clássicos de tornar científica a nossa atividade: transformar a ciência centrípeta que fazemos, estacionada entre as humanidades e a ciência, em ciência centrífuga, em diálogo íntimo com todos os saberes, incluindo os das outras ciências sociais. Nomeadamente, deve reconhecer-se a sociabilidade moderna como um caso especial das associações que caracteriza a matéria e a energia cósmicas. Nesse quadro, a sociabilidade moderna é muito mais próxima das outras sociabilidades humanas, como as tradicionais ou primitivas, e de sociabilidades animais estudadas pela etologia, do que geralmente é pensado. Esse reconhecimento reporá na devida escala os objetos de estudo naturais e humanos (Bateson, 1979; Mead, 1980). Passar a considerar a experiência da humanidade como objeto de estudo (Morris, 2013), em vez das imaginárias nações (Anderson, 1998), seria uma das primeiras consequências e pontos de partida das ciências sociais centrífugas.

\section{Referências bibliográficas}

AM AR AL, Diogo Freitas do - Do 11 de Setembro à crise do Iraque. Lisboa: Bertrand, 2003. ISBN 9-7225-1283-8. 
AMARAL, João Ferreira do [et al.] - Ciência económica vai nua. Público [em linha]. 2008. [consult. 10 set. 2010]. Disponível em http://www.publico.pt/opiniao/ jornal/a-ciencia-economica-vai-nua-286514.

AN DERSON, Benedict - Imagined Communities. Londres: Verso, 1998. ISBN 1-7847-8675-6.

BATESON, Gregory - Mind and Nature, a necessary unity. Nova Iorque: E.P. Dutton, 1979. ISBN 978-157-2734-34-0.

BELL, Daniel - The Coming of Post-Industrial Society: A Venture in Social Forecasting. Nova Iorque: Basic Books, 1973. ISBN 9-78-046-5012-81-7.

BURAWOY, Michael - For a Sociological Marxism: The Complementary Convergence of Antonio Gramsci and Karl Polanyi. Politics \& Society. USA. ISSN 0032-3292. 31: 2 (2004), p. 193-261.

CASANOVA, José Luís; Almeida, João Ferreira de - When Democracy Incubates Inequality and Heternomy. Sociologia, Problemas e Práticas. Lisboa. ISSN 0873-6529. 96 (2021), p. 9-40.

CASTELLS, Manuel - A Galáxia Internet: Reflexões sobre a Internet, Negócios e Sociedade. Lisboa: Fundação Caloust Gulbenkian, 2004. ISBN 9-78-972-3110-65-4.

CHRISTIAN, David - Education revolution with Big History. [em linha]. Lausanne: Frontiers. 2021 [consult. 10 abr. 2021]. Disponível em: https://www.youtube.com/ watch?v=JhowXxz_uAs.

CLARK, Nigel; SZERSZ YNSKI, Bronislaw - Planetary Social Thought: The Anthropocene Challenge to the Social Sciences. Londres: Polity Press, 2020. ISBN 978-1-509-52635-2.

COSER, Lewis A. - The Functions of Social Conflict. Londres: Free Press, 1956. ISBN 978-002-9068-00-7.

COSTA, António Firmino da - Será a Sociologia Profissionalizável?. In GONÇALVES, Carlos Manuel; RODRIGUES, Eduardo Vitor; AZEVEDO, Natália (Eds.) - Sociologia no Ensino Superior: Conteúdos, Práticas Pedagógicas e Investigação. Porto: Faculdade de Letras da Universidade do Porto, 2004. p. 35-58.

DAM ÁSIO, António - O erro de Descartes: emoção, razão e cérebro humano. Lisboa: EuropaAmérica, 1994. ISBN 9-78-989-6441-63-0.

DAM ÁSIO, António-Sentire Saber. Lisboa: Círculo de Leitores, 2020. ISBN 9-78-989-6445-40-9.

DARHENDORF, Ralf - Out of Utopia: Toward a reorientation of Sociological Analysis. A merican Journal of Sociology. Chicago. ISSN 0002-9602. 64: 2 (1958), p.115-127.

DORES, António Pedro - Espírito de Proibir. Lisboa: Argusnauta, 2010. ISBN 9-78-989-6830-06-9.

DORES, António Pedro - Dimensões sociológicas e a sua/nossa dependência das ideologias e do império: Teorias e Metodologias. Actas do VIII Congresso Português de Sociologia. Évora: Universidade de Évora, 2014.

DORES, António Pedro - Pós-verdade e pós-ciências sociais: da vontade e da possibilidade de autocrítica. Actas do X Congresso Português de Sociologia. Covilhã: Universidade da Beira Interior, 2019.

DORES, António Pedro - O Estado Social Real. Cascais: RCP edições, 2020. ISBN 9-78-98-983-2565-5.

FERREIR A, Fátima Campos - Sim ou não às praxes? [em linha]. 2014. Lisboa: RTP. [consult. 20 fev. 2015]. Disponível em: http://www.rtp.pt/programa/tv/p30738/e4.

FOUCAULT, Michel - Microfísica do Poder. Rio de Janeiro: Graal, 1999 [1984]. ISBN 9-78-85-703-8074-6

FRAGOSO, José - Deus Cérebro [em linha]. 2021. Lisboa: RTP2. [consult. 10 abr. 2021]. Disponível em: https://www.rtp.pt/play/p8309/e516990/deus-cerebro.

FREIRE, João (coord) - As Profissões em Portugal. Oeiras: Celta, 2003. 
GUIBEN TIF, Pierre (Ed.) - O ensino das teorias sociológicas em debate - Simpósio da ESPP. 2018. Lisboa: ISCTE-IUL. [consult. 11 dez. 2018]. Disponível em: http://cadeiras.iscte-iul. pt/TS3/ts2_1k_Simposio_2018_prog.htm.

HARARI, Yuval Noah - Homo Deus; História Breve do Amanhã. Lisboa: Editora Elsinore, 2018. ISBN 9-78-98-988-5529-9.

H AW KING, Stephen - A Brief History of Time: from the Big Bang to Black Holes. Nova Iorque: Bantan Books, 1988. ISBN 9-78-05-531-7325-3.

ISCTE-IUL - Relatório de Inserção na Vida A tiva dos Diplomados em 2018/2019 - Inquérito aos Diplomados do 10 Ciclo (um ano após a conclusão da licenciatura). Lisboa: ISCTE, 2021.

LATOUR, Bruno - Aramis et l'amour des techniques. Paris: La Découverte, 1992. ISBN 978-0-674-04323-7

LATOUR, Bruno - Changer de société, refaire de la sociologie. Paris: La Découverte, 2007. ISBN 9-78-27-071-5327-2.

LLANO, Sephan - The Relationship between Facts, Debate, and Education. Academia Letters Article 131 (2021). Disponível em: https://doi.org/10.20935/AL131.

LYON, David - Surveillance Society. Reino Unido: Open University Press, 2001. ISBN 9-78-03-352-0546-2.

MACHADO, Fernando Luís - Profissionalização dos Sociólogos em Portugal - contextos, recomposições e implicações. Sociologia, Problemas e Práticas. Lisboa. ISSN 0873-6529. 20 (1996), p. 43-103.

MEAD, George Herbert - The Philosophy of the Present. Chicago: The University of Chicago Press, 1980. ISBN : 9-78-15-739-2948-6.

MERTON, Robert K. - Discussion. American Sociological Review. USA. ISSN 1939-8271. XIII (1948), p. 164-168.

MORRIS, Ian - O Domínio do Ocidente. Lisboa: Bertrand, 2013. ISBN 9-78-97-225-2715-6.

MOUZELIS, Nicos - Sociological Theory: What Went Wrong? - diagnosis and remedies. Londres: Routledge, 1995. ISBN 9-78-04-150-7694-4.

O NEIL, Cathy - Weapons of Math Destruction. Londres: Penguin Books, 2016. ISBN 0-55-34-1881-5.

PER KINS, John - Confessions of an Economic Hit Man. Oakland: Berrett-Koehler Publishers, 2004. ISBN 9-78-00-919-0910-9.

PISTOR, Katharina - The Code of Capital: how the law creates wealth and inequality. Princeton: Princeton University Press, 2019. ISBN 9-78-06-911-7897-4.

POLAN YI, Karl - A Grande Transformação: as origens da nossa época. Rio de Janeiro: Editora Campus, 1980. ISBN 9-78-85-352-5076-3.

PRIGOGINE, Ilya - O Fim das Certezas. Lisboa: Gradiva, 1996. ISBN 9-78-97-266-2512-4.

QUARESM A, Luís António C. - Ser Sociólogo: A construção profissional de um ethos. Pistas para a profissionalização dos sociólogos em contexto não académico. Sociologia Online. Lisboa. ISSN 1647-3337. 9 (2015), p. 161-188.

REICH, Robert B. - O Trabalho das Nações. Lisboa: Quetzal, 1991. ISBN 972-564-177-9.

SCHOFIELD, Jim - The Real Philosophy of Science. Pacif Grove: Smashwords, 2018. ISBN 9-78-04-640-8190-6.

SKIDELSKY, Robert - Money and Government, a challenge to mainstream economics. London: Penguin Books, 2018. ISBN 9-78-01-419-8861-0.

STAPLES, William G. - The Culture of Surveillance: Discipline and Social Control in the USA. Nova Iorque: St. Martin Press, 1997. ISBN 9-78-03-121-8028-7.

SUPIOT, Alain - La gouvernance par les nombres. Paris: Fayard, 2015. ISBN 9-78-22-136-8109-2 .

VAROUFAKIS, Yanis - Comportem -se como adultos: a minha luta contra o establishment na Europa. Lisboa: Marcador, 2017. ISBN 9-78-98-975-4339-5. 
WACQUAN T, Loïc - As Prisões da Miséria. Oeiras: Celta, 2000. ISBN 972-774-085-5.

WEBER, Max - Politics as Vocation. [Em linha]. (2012a [1919]). [consult. 11 dez. 2018]. Disponível em: http://anthropos-lab.net/wp/wp-content/uploads/2011/12/Weber-Politicsas-a-Vocation.pdf.

WEBER, Max - Science as Vocation. [Em linha]. (2012b [1919]).[consult. 11 dez. 2018]. Disponível em: http://anthropos-lab.net/wp/wp-content/uploads/2011/12/Weber-Scienceas-a-Vocation.pdf.

WOODIW ISS, Michael - Crime, Crusades and Corruption: Prohibitions in the United States, 1900 -1987. Londres: Piter Publisher, 1988. ISBN 9-78-03-892-0796-2.

WOODIWISS, Michael - Gangster Capitalism: The United States and the Global Rise of O rganized Crime. Londres: Constable, 2005. ISBN 9-78-07-867-1671-5.

- Receção:12.04.2021

- Aprovação: 14.06.2021 